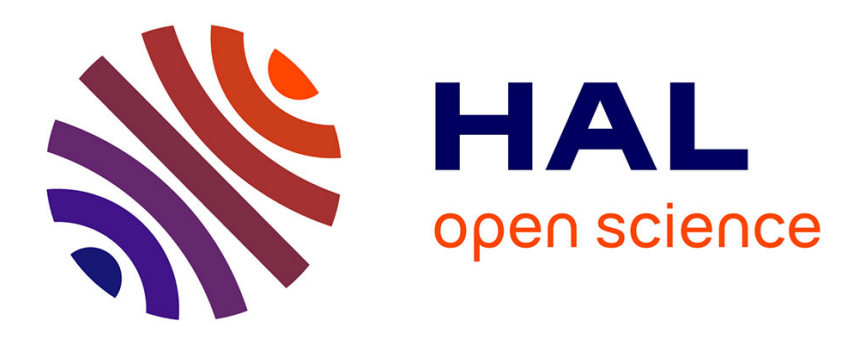

\title{
Dynamical deformation of a flat liquid-liquid interface
}

\author{
N. Dietrich, S. Poncin, H.-Z. Li
}

\section{To cite this version:}

N. Dietrich, S. Poncin, H.-Z. Li. Dynamical deformation of a flat liquid-liquid interface. Experiments in Fluids, 2011, 50 (5), pp.1293-1303. 10.1007/s00348-010-0989-7 . hal-00606327

\section{HAL Id: hal-00606327 \\ https://hal.science/hal-00606327}

Submitted on 23 Jul 2021

HAL is a multi-disciplinary open access archive for the deposit and dissemination of scientific research documents, whether they are published or not. The documents may come from teaching and research institutions in France or abroad, or from public or private research centers.
L'archive ouverte pluridisciplinaire HAL, est destinée au dépôt et à la diffusion de documents scientifiques de niveau recherche, publiés ou non, émanant des établissements d'enseignement et de recherche français ou étrangers, des laboratoires publics ou privés. 


\title{
DYNAMICAL DEFORMATION OF A FLAT LIQUID-LIQUID INTERFACE
}

\author{
Nicolas Dietrich*, Souhila Poncin and Huai Z. LI
}

Laboratoire des Sciences du Génie Chimique, Nancy-Université, CNRS, 1 rue Grandville, BP 20451, 54000

Nancy Cedex, France

* To whom correspondence should be addressed.

Tel.: +33(0)3 831753 67, Fax: +33 (0)3 8332 29 75, E-mail: Dietrich@ensic.inpl-nancy.fr

Keywords: Liquid-liquid interface, settling sphere, rising bubble, flow fields, PIV

\begin{abstract}
The present study aims at investigating experimentally the phenomena related to the passage of a solid sphere at a liquid-liquid interface by means of a high-speed digital camera and a Particle Image Velocimetry (PIV) system. Experiments were conducted in a square Plexiglas column of $0.1 \mathrm{~m}$. The Newtonian Emkarox (HV45 $50 \%$ and $65 \% \mathrm{wt}$ ) aqueous solutions were employed for the dense phase while different silicone oils of different viscosity ranging from 10 to $100 \mathrm{mPa}$.s were used as light phase. Experimental results allow to quantify the effect of the sphere's size, interfacial tension and viscosity of both phases on the retaining time and the height of the liquid entrained behind the sphere. The experimental data were gathered with our previous results concerning the passage of a rising bubble through liquid-liquid interface in order to develop a general relationship for the interface breakthrough in the wide range of $M o_{1} / \mathrm{Mo}_{2} \in\left[2 \times 10^{-5}-5 \times 10^{4}\right]$ and $\mathrm{Re}_{1} / \mathrm{Re}_{2} \in$ $\left[2 \times 10^{-3}-5 \times 10^{2}\right]$.
\end{abstract}

\section{Introduction}

The deformation of a liquid-liquid interface is of both academic and industrial interest. The coalescence between two oil drops in an emulsion depends to a large extent on the drainage and rupture of an aqueous liquid film. The knowledge on the behaviour of a liquid-liquid interface is then crucial for modelling the coating process involve the application of a thin film of functional material to a substrate (such as roll of paper, film, sphere or other textile) to enhance and alter the physical properties and appearance of a fabric. This has wide industrial applications such as fluidised bed, granular packing, separation or mixing processes. Only a few studies have been devoted to the breakthrough problem since then, most of them considering the approach of a sphere or a drop to a deformable interface with a focus on the coalescence such as Jones et al. (1978) or the motion near the interface like Danov et al. (1998). Hartland et al. (1968) studied the crossing of an interface by rigid spheres of homogeneous and non-homogeneous density. They noted that the spheres of non-homogeneous density tended to take a rotational movement when approaching the interface. This phenomenon is due to the dissymmetrical drainage of the liquid behind a sphere. These authors added that the presence of surfactants reduce the number of revolutions, making the drainage more symmetrical. Maru et al. (1971) used a camera to visualize the sedimentation of a rigid sphere through various liquid-liquid interfaces. They proposed a correlation of a critical radius of the sphere below which the sphere remains held up at the interface. When it crosses the interface, the sphere entrains a column of light liquid in the dense phase. The volume of this column increases with the sphere's diameter and decreases with the interfacial tension as well as the viscosity of the light phase. In the dense phase, the sphere first accelerates during its fall until the rupture of the column of the light liquid and reaches finally a constant velocity, accompanied by a fraction of the light fluid. The distance between the initial position of the interface and the rupture point decreases with the interfacial tension. After the film rupture, instabilities appear in the column of the light liquid during its getting back to the interface. Pitois $e t$ al. (1999) studied the passage of a sphere through a liquid-liquid interface in the special case of a highly viscous light phase (The viscosity ratio between light and dense phases is higher than 1000, and the diameters of spheres range from 1 to $2.5 \mathrm{~mm}$ ). The authors defined a modified Bond number:

$$
B o=\frac{R^{2} \Delta \rho g}{\sigma_{12}} \text { (1) }
$$


For low values of the modified Bond number Bo two distinct regimes were observed: a slow draining stage of the upper liquid film of light phase trapped between the sphere and the interface and a rapid one where a liquid tail bridges the sphere to the upper phase. It is found that the volume of liquid carried away by the sphere varies as $\ln (\mathrm{Bo})$ and that the time necessary for breakthrough is proportional to $1 / \ln (\mathrm{Bo})$. Chateau and Pitois (2003) studied the problem of removing a spherical particle initially attached to a liquid-gas interface. They proposed the correlations corresponding to the prescribed displacement and the applied force conditions, which seem to be the relevant to the flotation separation process. Their results show that these correlations are sufficiently accurate to estimate the energy required for the sphere to detach from the interface as soon as the sphere's radius is smaller than the capillary length. On the numerical and theoretical side, very few works were carried out for the deformation of the liquid-liquid interface. Geller et al. (1986) studied numerically the approach of a rigid sphere normal to a deformable liquid-liquid interface under the creeping motion condition to neglect inertial effects. The motion of a sphere with a constant velocity or a constant non-hydrodynamic body force was respectively considered for several values of the viscosity ratio, density difference and interfacial tension between both liquids. Two distinct modes of interface deformation were demonstrated: a film drainage mode in which fluid drains away in front of the sphere leaving an ever-thinning film, and a tailing mode where the sphere passes several radii beyond the initial plane of the liquid-liquid interface. After the crossing, the sphere remains encapsulated by the original light liquid which is connected with its main body by a thin thread-like tail behind the sphere. As a benchmark problem in the literature, numerous works have been devoted to the sedimentation of a solid sphere in both Newtonian fluids (Harrison et al. (2001); Tatum et al. (2005)) and nonNewtonian fluids (Chhabra et al. (1981); Mena et al. (1987); Tirtaatmadja et al. (1990)).

Iin the literature, a few works (Lin \& Slattery 1982, Chen et al. 1984, Bataille et al. 1991, Kemiha et al. 2007 and Satoh et al. 2008) were devoted to the penetration of bubbles or drops through liquid-liquid interfaces composed of two immiscible liquids. These studies present plausible scenarios related to the interface breakthrough when bubbles or drops migrate from a phase to another. Mohamed-Kassim \& Longmire (2004) examined the coalescence of drops through liquid/liquid interfaces using a Particle Image Velocimetry (PIV). Dietrich et al. (2008) made also use of a PIV to measure the velocity profile around a bubble passing through an interface. However, to our best knowledge, the deformation of a flat liquid-liquid interface due to the passage of a sphere was not yet investigated by a PIV in literature.

The present work aims at investigating, by means of a high speed camera as well as a PIV system, the solid sphere passage at an immiscible liquid-liquid interface formed by a heavy and a light, both Newtonian liquids. Quantitative information concerning the different configurations of sphere passage could lead to a better understanding of these complex phenomena.

\section{Experimental setup}

The experiments were conducted in a square Plexiglas column (inner dimensions: $10 \mathrm{~cm}$ width, $0.50 \mathrm{~m} \mathrm{high}$ ) filled with different couples composed of oil and aqueous phases. The spheres used in our study were glass particles with a density of $2520 \mathrm{~kg} \cdot \mathrm{m}^{-3}$ and diameter of $4 \times 10^{-3} \mathrm{~m}$ and $6 \times 10^{-3} \mathrm{~m}$. These diameters were chosen in order to make possible interface rupture before the arrival of the sphere at the bottom of the column. The spheres were released at the top of the column using a computer assisted trigger, at a sufficient height with respect to the interface to reach their terminal velocity in the upper light phase. In these experiments, the spheres were always settled individually to minimize the flow interaction between two consecutive sedimenting spheres. All experiments were carried out at a constant temperature of $293 \mathrm{~K}$.

Table 1. Properties of the different liquids used in this study

\begin{tabular}{cccc}
\hline Fluid & Viscosity $($ Pa.s $)$ & Density $\left(\mathrm{kg} \cdot \mathrm{m}^{-3}\right)$ & Surface tension in air $\left(\mathrm{mN} \mathrm{m}^{-1}\right)$ \\
\hline Silicone oil 100 & $100.10^{-3}$ & 965 & 20.15 \\
Silicone oil 50 & $50.10^{-3}$ & 962 & 20.2 \\
Silicone oil 10 & $10.10^{-3}$ & 958 & 20.3 \\
Emkarox 50\% $(\mathrm{wt})$ & $205.10^{-3}$ & 1032.6 & 47.5 \\
Emkarox 65\% (wt) & $515.10^{-3}$ & 1052.2 & 48.5 \\
\hline
\end{tabular}

The visualisation of the phenomenon was realised by a high-speed digital video camera (VNR 950, SYSMA INDUSTRIE) at a rate of 950 images per second, for record grey valued images with a size of $256 \times 256$ pixels. The light was provided by an indirect $800 \mathrm{~W}$ halogen which enlightened the column via indirect lighting on a white screen placed behind the column. The image sequences obtained were then analysed in order to compute 
the sphere position, the velocity and the liquid drained behind the sphere. In this work, three different liquids were employed as light phase: Silicone oil 47V10, Silicone oil 47V50 and Silicone oil 47V100. The liquids used as dense phase were viscous Newtonian Emkarox $50 \%$ and $65 \%$ wt HV45 dilute solutions in demineralised water. A Rheometric Fluid Spectrometer RFS II (Rheometric Scientific, USA) was employed to measure the rheological properties (Table 1).

Table 2. Various parameters of the different liquid-liquid systems used in this work

\begin{tabular}{|c|c|c|c|c|c|c|c|c|c|c|c|c|}
\hline Phase 1 : After interface crossing & \multicolumn{6}{|c|}{ HV45 $50 \%$} & \multicolumn{6}{|c|}{ HV45 $65 \%$} \\
\hline $\begin{array}{c}\text { Phase } 1 \text { : Before interface } \\
\text { crossing }\end{array}$ & \multicolumn{2}{|c|}{ HS10 } & \multicolumn{2}{|c|}{ HS50 } & \multicolumn{2}{|c|}{ HS100 } & \multicolumn{2}{|c|}{ HS10 } & \multicolumn{2}{|c|}{ HS50 } & \multicolumn{2}{|c|}{ HS100 } \\
\hline Interfacial tension $10^{-3}\left(\mathrm{~N} \cdot \mathrm{m}^{-1}\right)$ & \multicolumn{2}{|c|}{15.2} & \multicolumn{2}{|c|}{13.4} & \multicolumn{2}{|c|}{11.2} & \multicolumn{2}{|c|}{14.9} & \multicolumn{2}{|c|}{13.1} & \multicolumn{2}{|c|}{11.8} \\
\hline Bond Number & \multicolumn{2}{|c|}{3.61} & \multicolumn{2}{|c|}{4.1} & \multicolumn{2}{|c|}{4.91} & \multicolumn{2}{|c|}{3.69} & \multicolumn{2}{|c|}{4.19} & \multicolumn{2}{|c|}{4.66} \\
\hline Sphere diameter $10^{-3}(\mathrm{~m})$ & 4 & 6 & 4 & 6 & 4 & 6 & 4 & 6 & 4 & 6 & 4 & 6 \\
\hline Sphere terminal velocity $\left(\mathrm{m} \cdot \mathrm{s}^{-1}\right)$ & 0.254 & 0.57 & 0.254 & 0.57 & 0.254 & 0.57 & 0.1 & 0.224 & 0.1 & 0.224 & 0.1 & 0.224 \\
\hline Sphere terminal velocity $2\left(\mathrm{~m} \cdot \mathrm{s}^{-1}\right)$ & 5.48 & 12.32 & 1.1 & 2.46 & 0.55 & 1.23 & 5.48 & 12.32 & 1.1 & 2.46 & 0.55 & 1.23 \\
\hline $\operatorname{Re}_{2}$ & 4.2 & 14.1 & 4.2 & 14.1 & 4.2 & 14.1 & 1.6 & 5.5 & 1.6 & 5.5 & 1.6 & 5.5 \\
\hline $\mathrm{Re}_{1}$ & 2092 & 7060 & 84 & 282 & 21 & 71 & 2092 & 7060 & 84 & 282 & 21 & 71 \\
\hline $\mathrm{Mo}_{2}$ & \multicolumn{6}{|c|}{0.87} & \multicolumn{6}{|c|}{15.33} \\
\hline $\mathrm{Mo}_{1}$ & \multicolumn{2}{|c|}{$1.76 \times 10^{-5}$} & \multicolumn{2}{|c|}{$8.03 \times 10^{-3}$} & \multicolumn{2}{|c|}{$9.65 \times 10^{-2}$} & \multicolumn{2}{|c|}{$1.76 \times 10^{-5}$} & \multicolumn{2}{|c|}{$8.03 \times 10^{-3}$} & \multicolumn{2}{|c|}{$9.65 \times 10^{-2}$} \\
\hline Time of passage $t_{p}(s)$ & 0.36 & 0.244 & 0.54 & 0.423 & 0.636 & 0.51 & 0.461 & 0.345 & 0.712 & 0.533 & 0.938 & 0.688 \\
\hline Characteristic time $t_{c}(s)$ & 0.0007 & 0.0005 & 0.0037 & 0.0024 & 0.007 & 0.005 & 0.0007 & 0.0005 & 0.004 & 0.0024 & 0.007 & 0.0049 \\
\hline$t_{\mathrm{p}} / \mathrm{t}_{\mathrm{c}}$ & 493 & 501 & 148 & 174 & 87 & 105 & 631 & 708 & 195 & 219 & 128 & 141 \\
\hline fluid $h_{\max }(m)$ & 0.11 & 0.162 & 0.126 & 0.207 & 0.131 & 0.19 & 0.107 & 0.16 & 0.164 & 0.237 & 0.136 & 0.179 \\
\hline
\end{tabular}

The surface and interfacial tensions of the solutions were measured using a Tracker tensiometer (I.T. Concept, France). The interfacial tension between phases is presented in Table 2. Instantaneous velocity fields around a sedimenting sphere were measured using a Particle Image Velocimetry (PIV, Dantec Dynamics, Denmark) device (Fig. 1). Illumination sheets were generated with two pulsed Nd-YAG LASERS (New Wave Research, USA) arranged side-by-side and crossed the vertical symmetry axis of the sphere. The energy produced by this source was $2 \times 15 \mathrm{~mJ}$. These lasers allowed the emission of a green light with a $532 \mathrm{~nm}$ wavelengths for a duration of 8 to $10 \mathrm{~ns}$. The time interval between the illuminations ranged from less than one microsecond to a few milliseconds. The sequence of illuminations by the Nd-Yag lasers was chosen at a frequency of $15 \mathrm{~Hz}$. The laser beams crossed first a cylindrical lens and obtained a laser sheet of strong light intensity and fine thickness ( $2.5 \mathrm{~mm}$ maximum). They were focused and superposed on one zone of measurement. The size of the seeding particles was chosen to follow suitably the flow and produce a sufficient detectable light signal to facilitate the image recording and minimize the measurement errors. They were composed of silvered glass microspheres of size ranging from 10 to 30 micrometers (average diameter of 15 micrometer) and of a density of $1400 \mathrm{~kg} . \mathrm{m}^{-3}$. These sizes allowed to minimize both the Brownian movement and sedimentation of seeding particles. The camera, placed perpendicular to the laser sheets, took two successive images at the maximum intensity of the laser impulse. These images were divided into a few thousands of small interrogation areas of $16 \times 16$ pixels. A cross-correlation was then performed between the corresponding interrogation areas with an overlap of $25 \%$. The liquid flow fields as well as the velocity of the sphere were thus obtained. When the liquid was correctly inseminated, the experimental errors of measured velocity were less than $5 \%$. These experiments led to the instantaneous settling sphere velocity at different positions in the column as well as its terminal velocity $U$.

\section{Sedimentation of a sphere}

Preliminary experiments of a settling sphere in a stagnant liquid were also conducted to obtain a comparison reference for the velocity field in the dense phase. The flow field around a $6 \mathrm{~mm}$ glass sphere settling in HV45 $50 \%$ wt solution is shown in Figure 2 with the components $\mathrm{u}$ and $\mathrm{v}$ of the velocity in the $\mathrm{x}$ - (lateral) and $\mathrm{y}$ (vertical) coordinate directions. The $\mathrm{u}-\mathrm{v}$ velocity measurements illustrate some typical flow features occurring in all settling sphere experiments. Obviously, liquid stagnation zones exist around the axe of the settling sphere on the lateral sides. The local $\mathrm{x}$ position at which the liquid stagnation begins appears to be independent upon the settling velocity. 
A large wake is observed behind the sphere. In front of the sphere the fluid is pushed out in both the vertical and lateral directions. Figure 2 shows that the vertical component of the velocity decays with increasing distance behind the sphere, and is close to zero after approximately ten sphere's diameter behind the sphere. Finally, it is worthy noting a perfect axisymmetry in the flow fields around the axe of the settling sphere. In order to validate the measurements of our PIV device, both the high-speed camera and PIV device were used to measure the sphere's settling velocity. The difference between two approaches is usually less than $3 \%$.

\section{Passage of sphere through an interface}

With respect to the classical settling of a sphere in a homogenous liquid, the passage of a sphere through a liquid-liquid interface is quite different. Both the interfacial force and viscous drag contribute simultaneously to the approaching and impact of the sphere towards the liquid-liquid interface. However, the drainage of the light liquid film between the sphere and the interface is progressive to prevent a rapid contact with the dense phase. When the film becomes sufficiently thin, intermolecular forces begin to play a significant role before its first rupture. Then, the sphere entrains a column of the light liquid into the dense phase through the interface. The rupture of this column of the light liquid behind the sphere occurs in the dense phase and the light liquid goes back to the interface under the combined effects of buoyancy and repulsion of the film break-up. Finally, the sphere continues its falls in the dense phase to reach its terminal settling velocity.

Figure 3a shows the different steps during the passage of a $4 \mathrm{~mm}$ glass sphere through the liquid-liquid interface composed of Silicone oil 10 (light phase)/HV45 50\% (dense phase). The initially flat interface begins the deformation at the arrival of the sphere. It was difficult to have systematically the rupture of the entrained light liquid due to the limited height of the dense phase for a wide range of sphere diameter, in particular for bigger spheres. The spheres having diameter of $4 \times 10^{-3} \mathrm{~m}$ and $6 \times 10^{-3} \mathrm{~m}$ were chosen to allow the visualisation of the rupture in all experiments. Moreover, the choice of these diameters avoided the eventual appearance of interfacial instabilities such as the finger pattern that could complicate the visualisation. Several behaviours of the interface crossing can be observed for the various liquid-liquid systems.

Firstly, there is a deceleration of the sphere in the vicinity of the interface because of the combined interfacial and viscous forces (Fig. 3b). This deceleration starts with the deformation of the interface with the approach of the sphere. Then the interface stretching occurs due to the light liquid entrained by the sphere. Finally, the rupture of the entrained column of light liquid takes place, usually in an intermediate position. In order to gain insight into these phenomena, the flow fields were measured by the PIV system in the vicinity of the liquidliquid interface as well as around the breaking position of the entrained column of light liquid. The physical properties of each system play a major role in both the time spent by the sphere at the interface and the stretch length of the entrained column of light liquid. To highlight this effect, Table 2 resumes the main parameters for various liquid-liquid interfaces and sphere sizes. The variation of the time spent by the sphere at the interface is represented by relevant dimensionless numbers. As viscosity and inertia forces are involved, the Reynolds number is chosen: $\operatorname{Re}_{1}$ and $\operatorname{Re}_{2}$ based on the terminal settling sphere velocities respectively in the dense and light phases. In Table 2, the diameter of the sphere and the passage time of the sphere ( $t_{p}$ is the time spent by the sphere to cross i.e. the interface between it first and last contact with interface, fig $3 \mathrm{~b}$ ) are also listed. Obviously, the passage time is significantly affected by the sphere diameter and the viscosity ratio between the dense and light liquid phases. The Reynolds number Re is a dimensionless number that gives a measure of the ratio of inertial forces to viscous forces and, consequently, it quantifies the relative importance of these two types of forces for given flow conditions with the following definition:

$$
\operatorname{Re}_{\mathrm{i}}=\frac{\rho_{\mathrm{i}} \mathrm{U}_{\mathrm{i}} \mathrm{d}_{\mathrm{eq}}}{\mu_{\mathrm{i}}}
$$

where $\mu_{\mathrm{i}}$ and $\rho_{\mathrm{i}}$ are respectively the viscosity and density of the surrounding fluid, $\mathrm{U}_{\mathrm{i}}$ is the velocity of the sphere in phase $\mathrm{i}$ and $\mathrm{d}_{\mathrm{eq}}$ the equivalent diameter.

In fluid dynamics, the Morton number (Mo) is a dimensionless number to characterize the impact of interfacial tension (Clift and Grace, 1979):

$$
\mathrm{Mo}_{\mathrm{i}}=\frac{g \mu_{\mathrm{i}}^{4}}{\rho_{\mathrm{i}} \sigma_{\mathrm{i}}^{3}}
$$

where $\mathrm{g}$ is the acceleration of gravity and $\sigma_{\mathrm{i}}$ is the interfacial tension. As shown in Figure $4 \mathrm{a}, t_{p}$ normally decreases with the increase of the sphere size for a given liquid-liquid system and increases with the viscosity of the dense or the light phase for a given sphere diameter. The same observations are done for the height of liquid $\mathrm{h}_{\max }$ entrained behind the sphere (Fig. $4 \mathrm{~b}$ ) 
In Table 2, the influence of the sphere diameter on the passage time $t_{p}$ is quite logic with the increase of inertial forces. A dimensionless number is defined on the basis of the passage time $t_{p}$ and a characteristic time of the sphere in the light liquid $t_{c}\left(t_{c}=d / U\right.$ is a approximately time spent by the sphere to travel an equivalent distance of its diameter and $U$ the terminal settling velocity of the sphere in the light phase):

$$
\frac{t_{p}}{t_{c}}=\frac{t_{p}}{d / U}
$$

Fig. 5a shows the variation of $t_{p} / t_{c}$ for spheres in function of the ratio of two Reynolds numbers in the dense and light phases $R e_{2} / \operatorname{Re}_{1}$. The experimental results under various conditions are well gathered by the following correlation (multi-parameters simplex optimisation) :

$$
\begin{aligned}
\frac{\mathrm{t}_{\mathrm{p}}}{\mathrm{t}_{\mathrm{c}}}= & 54.4\left(\frac{\operatorname{Re}_{1}}{\operatorname{Re}_{2}}\right)^{0.35}(5) \\
& \operatorname{Re}_{1} / \operatorname{Re}_{2} \in\left[5-2 \times 10^{3}\right]
\end{aligned}
$$

Concerning the height of the liquid entrained behind the particles, it was also measured for two sizes of bubbles and spheres for the six liquid-liquid interfaces studied. Figure $5 \mathrm{~b}$ represents the evolution of the dimensionless ratio $h / d_{e q}$ between the maximum height of liquid entrained and the particle diameter as a weak function of the Reynolds number ratio $\mathrm{Re}_{1} / \mathrm{Re}_{2}$.

$$
\begin{aligned}
& \frac{\mathrm{h}_{\mathrm{max}}}{\mathrm{d}_{\mathrm{eq}}}=37\left(\frac{\mathrm{Re}_{1}}{\mathrm{Re}_{2}}\right)^{-0.07} \text { (6) } \\
& \operatorname{Re}_{1} / \operatorname{Re}_{2} \in\left[5-2 \times 10^{3}\right]
\end{aligned}
$$

The measurement of flow fields can gain further information about the breakthrough mechanism of the liquid film. The major difficulty in applying the PIV technique to characterize free surface flows in the vicinity of the interface arises from the light reflection at the interface. Such reflection at the interface could be sometimes more intense than the light scattered by the seeding particles to complicate to some extent their location. The seeding particles were glass microspheres with a mean diameter of $15 \mu \mathrm{m}$ and employed in both liquid phases. Figure 6 illustrates an example of the optical reflection at the interface as well as the shadow zone in the sphere back. A particular attention was paid to reduce these optical effects in the determination of the flow fields.

The experimental flow fields obtained during the sphere settling through the Silicone oil 100/HV45 50\% interface are shown in Figures 7 and 8 respectively for spheres of $4 \times 10^{-3} \mathrm{~m}$ and $6 \times 10^{-3} \mathrm{~m}$ diameter. The time interval between two successive frames to determine the flow fields was $5 \times 10^{-3} \mathrm{~s}$. The choice of this short time is necessary in view of the rapidity of the physical phenomena. To facilitate the visualization, the interface (dashed line) and the sphere shape are added in the flow fields (Figs. $7 \& 8$ ). During the fall of the sphere in the light phase, no significant change is observed in the dense phase far from the interface. The resulting flow field is similar to that obtained for the sedimentation in an infinite with a downward flow at the front and in the wake of the sphere and recirculation loops on the sides of the sphere. When the sphere approaches the interface (Fig. 7a), the liquid-liquid interface is deformed due to the downward flow at the front of the sphere. When the sphere crosses the liquid-liquid interface, a column of light liquid is entrained (Figs. $7 \mathrm{~b}$ and 8a) with the appearance of lateral circulation loops adjacent to the sphere in the dense phase. Figures $7 \mathrm{c}$ and $8 \mathrm{c}$ show the progressive stretching and thinning of the column of the light liquid behind the sphere. One can also observe (Figs. 7d \& 8d) the existence, at a certain height around this column of light liquid, of opposed flow directions: an upward flow inside the column and also a downward flow just behind the sphere in the dense liquid. This upward flow is due to the interface elasticity and especially to the buoyancy ascension of the light phase entrained in the dense one. A nearly plate plan does exist separating these two opposed flows. The downward and upward flows stretch the film in different directions leading to its subsequent rupture which explains why the rupture occurs usually in the middle of the column of the light liquid. Additional circulation loops appear for the bigger sphere in the dense phase near the interface. This behaviour, which does not occur for the smaller sphere, contributes to the progressive thinning of the column of the light liquid until to its rupture. The symmetric flow pattern illustrates also the measurement accuracy of the flow fields in spite of some optical effects that are efficiently reduced. After the rupture, the sphere falls in the dense phase and the column of light liquid goes back to its own phase, along with the formation of droplets due to the break-up of the thin film.

\section{Generalization for the passage of both bubble and sphere}

Figures $5 \mathrm{a}$ and $5 \mathrm{~b}$ show the dependency of $t_{p} / t_{c}$ and $h_{\max } / d_{e q}$ on the ratio of Reynolds numbers $\operatorname{Re}_{1} / \operatorname{Re}_{2}$ for both solid spheres and gas bubbles Dietrich et al. (2008). The complementary range of the experimental conditions 
$\left(\operatorname{Re}_{1} / \operatorname{Re}_{2} \in\left[5-2 \times 10^{3}\right]\right.$ for spheres and $\operatorname{Re}_{1} / \operatorname{Re}_{2} \in\left[2 \times 10^{-3}-5 \times 10^{-1}\right]$ for bubbles) is particularly interesting. It is worthy noting a similar tendency between these two curves. The experimental results for bubbles were well gathered under various conditions by the following correlation (Dietrich et al. 2008):

$$
\begin{aligned}
& \text { For bubbles: } \frac{\mathrm{t}_{\mathrm{p}}}{\mathrm{t}_{\mathrm{c}}}=2.7\left(\frac{\mathrm{Re}_{1}}{\mathrm{Re}_{2}}\right)^{\frac{1}{3}} \\
& \operatorname{Re}_{1} / \operatorname{Re}_{2} \in\left[2 \times 10^{-3}-5 \times 10^{-1}\right]
\end{aligned}
$$

Clearly, both correlations for spheres and bubbles have a similar exponent around 0.33 with a quite prediction accuracy (relative error less than $3 \%$ for each). Certainly, due to the difference of the proportional coefficient in the power law, there is still a discontinuity as shown in Fig. 5a. This could be due to the fact that the interfacial forces were not taken into account in the equations (5) and (7). A Morton number ratio Mo1/Mo2 between two phases was then added in the previous correlations. The following dimensionless correlation was obtained based on all experimental data including spheres and bubbles:

$$
\begin{gathered}
\frac{\mathrm{t}_{\mathrm{p}}}{\mathrm{t}_{\mathrm{c}}}=9.6\left(\frac{\mathrm{Re}_{1}}{\mathrm{Re}_{2}}\right)^{2.76}\left(\frac{\mathrm{Mo}_{1}}{\mathrm{Mo}_{2}}\right)^{1.27} \text { (8) } \\
M o_{1} / \mathrm{Mo}_{2} \in\left[2 \times 10^{-5}-5 \times 10^{4}\right] \text { and } \operatorname{Re}_{1} / \operatorname{Re}_{2} \in\left[2 \times 10^{-3}-5 \times 10^{2}\right]
\end{gathered}
$$

The average relative error is about $17.7 \%$ with a maximum error of $30.9 \%$. Fig. 8 shows a good agreement between the experimental values of $t_{\mathrm{p}} / \mathrm{t}_{\mathrm{c}}$ and the global correlation for a wide range of Morton number $M o \in\left[10^{-}\right.$ $\left.{ }^{4}-10^{4}\right]$. Concerning the height of the liquid entrained behind the particles, Fig. $5 \mathrm{~b}$ represents the evolution of the dimensionless ratio $h / d_{e q}$ between the maximum height of liquid entrained and the particle diameter as a function of the Reynolds number ratio $R e_{1} / R e_{2}$ for both spheres and bubbles. As for the case of the passage time, a Morton number ratio $\mathrm{Mo}_{1} / \mathrm{Mo}_{2}$ was also used to take into account the influence of the interfacial forces. The following dimensionless correlation allows to gather well all experimental data:

$$
\frac{\mathrm{h}_{\text {max }}}{\mathrm{d}_{\mathrm{eq}}}=19.82\left(\frac{\mathrm{Re}_{1}}{\mathrm{Re}_{2}}\right)^{1.17}\left(\frac{\mathrm{Mo}_{1}}{\mathrm{Mo}_{2}}\right)^{0.65}
$$

$$
M o_{1} / \mathrm{Mo}_{2} \in\left[2 \times 10^{-5}-5 \times 10^{4}\right] \text { and } \operatorname{Re}_{1} / \operatorname{Re}_{2} \in\left[2 \times 10^{-3}-5 \times 10^{2}\right]
$$

A satisfactory agreement is obtained as shown in Figure 10 with a mean relative error less than $8.4 \%$ for $M o \in\left[10^{-5}-15.4\right]$.

\section{Flow instabilities}

The above proposed correlations (Eqs. 8 \& 9) take into account the liquid physical properties and interfacial tension to predict the passage time $t_{p}$ of both spheres and bubbles and also the quantity of fluid displaced after the interfaces crossing $h_{\max }$. These could be useful tools for coating and mixing process design, however, their application ranges $\mathrm{Mo}_{1} / \mathrm{Mo}_{2} \in\left[2 \times 10^{-5}-5 \times 10^{4}\right]$ and $\operatorname{Re}_{1} / \operatorname{Re}_{2} \in\left[2 \times 10^{-3}-5 \times 10^{2}\right]$ are limited by two major phenomena. For the upper limit of this last dimensionless number, no passage is possible for very small spheres and bubbles that are blocked at the interface (typically, diameter of $1 \mathrm{~mm}$ and less). For very big spheres and bubbles, peculiar flow instabilities are observed as shown in Fig. 11. For $\mu_{1} / \mu_{2}<10^{-2}$ and $\sigma \sim 0.02 \mathrm{~N} . \mathrm{m}^{-1}$, instabilities are observed at the interface just behind the sphere or bubble. These instabilities could stemp from a combined effect between the Rayleigh-Taylor instability due to the density difference between two phases and the Kelvin-Helmholtz instability with velocity difference across the interface. Further experimental studies are still required for clarifying the origin. From the industrial viewpoint such as coating, emulsification and mixing processes, the understanding and control of the deformation of viscous layers provide useful guidelines for avoiding the onset of hydrodynamics instabilities to improve the quality of the end product. Our above simple criterion allows to predict the apparition of such instabilities.

\section{Conclusion}

This work presents some original results regarding the liquid-liquid interface breakthrough by the passage of a settling solid sphere. New experimental results including both the flow fields by the PIV measurements and the visualisation by the high speed camera are obtained under various conditions: two sizes of solid sphere, six Newtonian fluid couples for liquid-liquid interfaces of different properties. Experimental results show a logical increase of the passage time of a sphere at the liquid-liquid interface with the decrease of both the sphere diameter and the viscosity of each liquid phase due to inertial and viscous drag effects. An empirical correlation based on the Reynolds numbers defined in each liquid phase has been proposed to estimate the passage time with a satisfactory agreement (average error less than $2 \%$ ). The flow field measurements obtained by the PIV device contribute to an original and better understanding of the different steps encountered during the film drainage and its thinning up until to its rupture. This paper can be a useful tool for simulations comparisons or 
coating and mixing reactor design taking into account the liquid physical properties and marks an original improvement in this domain. Further experiments with different physical properties of liquids and spheres at different scales could hopefully provide new insight into the fundamental understanding of interfacial phenomena as well as the mathematical modelling such as the Lattice Boltzmann (LB, Frank et al., 2006) or Volume of Fluid (VOF, Kemiha et al., 2007) approaches. By gathering all experimental data including our previous results related to the bubble passage at a liquid-liquid interface, a global correlation based on the Reynolds numbers ratio $\operatorname{Re} \in[0.8-7907]$ and Morton numbers ratio Mo $\in\left[10^{-5}-15.4\right]$ between phases for describing the deformation of a liquid-liquid interface due to the passage of both spheres and bubbles. This correlation culd be useful for a wide range of industrial applications such as coating, emulsification, mixing processes.Finally, some interesting flow instabilities occur at the liquid-liquid interface under peculiar conditions such as for low viscosity ratios. The origine could stem from a dual action of Rayleigh-Taylor instability and Kelvin-Helmholtz instability. A viscosity ratio between two phases seems to be a reliable criterion for the apparition of such phenomena. Further investigations with extended physical properties of liquid-liquid interfaces are required to understand the physical mechanism of the apparition of interface instabilities and then to remain the stable quality of final products in some typical industrial processes like coating.

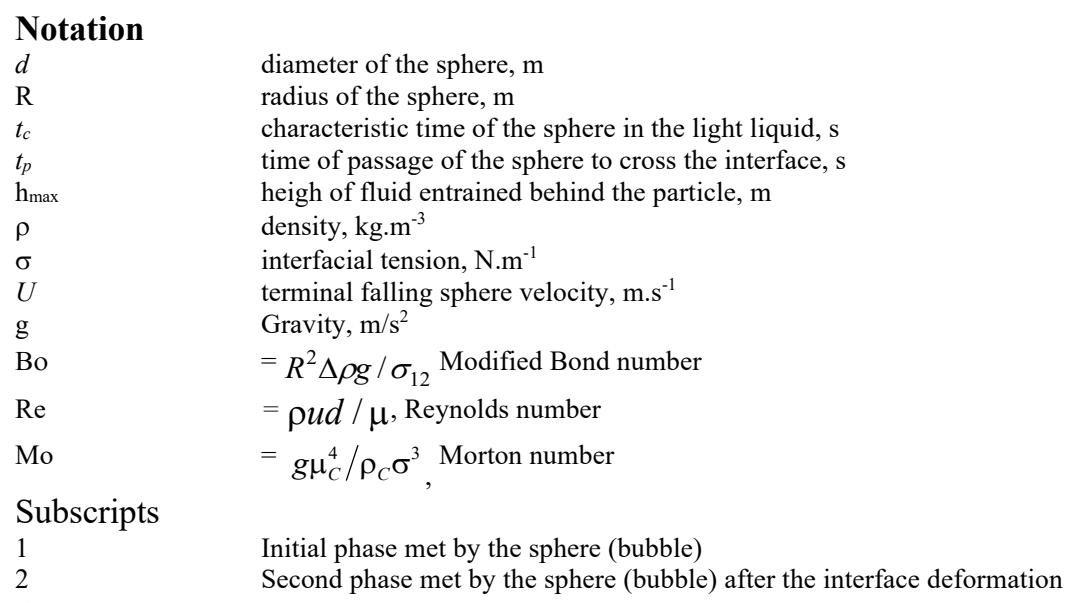

Second phase met by the sphere (bubble) after the interface deformation

\section{Acknowledgements}

The financial assistance provided by the French Ministère de l'Enseignement Supérieur et de la Recherche is gratefully acknowledged.

\section{Literature cited}

1. Bataille, J., Lance, M. et Marie, J. L. (1991). Some Aspect of the Modelling of Bubbly Flows. In Phase-Interface Phenomena in Multiphase Flow, ed. G.F., Hewitt, F., Mayinger, J.R., Riznic, pp. 179193.

2. Chateau X., Pitois O., (2003), Quasistatic detachment of a sphere from a liquid interface Journal of Colloid and Interface Science, 259, 346-353.

3. Chen, J. D., Hahn, P. S. et Slattery, J. C. (1984). Coalescence time for a small drop or bubble at a fluidfluid interface. AIChE Journal, 30 , 622-630.

4. Chhabra R.P., Tiu C., Uhlherr P.H.T., (1981), Creeping motion of spheres through Ellis model fluids, Rheol. Acta, 20, 346-351.

5. Clift, R., Grace, J. R. et Weber, M. E. (1978). Bubbles, Drops et Particles. Academic press, NewYork, USA.

6. Danov K. D., Gurkov T. D., Raszillier H. and Durst F., (1998), Stokes flow caused by the motion of a rigid sphere close to a viscous interface, Chemical Engineering Science, 53, 3413-3434.

7. Dietrich N., Poncin S., Pheulpin S. and LI H.Z, (2008). Passage of a bubble through a liquide-liquide interface. AICHE J. 2008, 54, 3, 594-600.

8. Frank X., Funfschilling D., Midoux N. \& Li H.Z. (2006). Bubbles in a viscous liquid: Lattice Boltzmann simulation et experimental validation. J. Fluid Mech., 546, 113-122

9. Geller A.S., Lee S.H., Leal L.G., (1986), The creeping motion of a spherical particle normal to a deformable interface, J. Fluid Mech, 169, 27-69. 
10. Harrison G.M., Lawson N.J., Boger D.V., (2001), The measurement of the flow around a sphere settling in a rectangular box using 3-dimensional particle image velocimetry, Chem. Eng. Commun., $188,143-178$.

11. Hartland S., (1968), The approach of a rigid sphere to a deformable liquid/liquid interface, J. Colloid Interf. Sci., 26, 383-394.

12. Jones A.F., Wilson S.D.R., (1978), The film drainage problem in droplet coalescence, J. Fluid. Mech., 87, 263-288.

13. Kemiha M., Olmos E., Fei W., Poncin S et Li H. Z. (2007), Passage of a gas bubble through a liquidliquid interface. Ind. Eng. Chem. Res., 46, 6099-6104.

14. Lin, C. Y. et Slattery, J. C. (1982). Thinning of a liquid film as a small drop or bubble approaches a fluid-fluid interface. AIChE Journal, 28, 798-792.

15. Maru H.C., Wasan D.T.. Kintner R.C., (1971), Behavior of a rigid sphere at a liquid-liquid interface. Chemical Engineering Science, 26, 1615-1628.

16. Mena B., Manero O., Leal L.G., (1987), The influence of rheological properties on the slow flow past spheres, J. Non-Newtonian Fluid Mech, 26, 247-275.

17. Mohamed-Kassim, Z. et Longmir E.K. (2004), Drop coalescence through a liquid/liquid interface. Physics of Fluids, 16, 2170-2181.

18. Pitois O., Moucheront P., Weill C., (1999), Franchissement d'interface et enrobage d'une sphère, Comptes Rendus de l'Académie des Sciences - Series IIB - Mechanics-Physics-Astronomy, 327, 605 611.

19. Rayleigh J.W.S. Proceedings of the London Mathematical Society. 1883, 14, 170-177.

20. Satoh, M., Aoki, K., Chen, J, (2008), Electrically Driven Motion of an Air Bubble on Hemispherical Oil/Water Interface by Three-Phase Boundary Reactions Langmuir, 24, 4364-4369

21. Tatuma J.A., Finnisb M.V., Lawsonc N.J., Harrisona G.M., (2005), 3D particle image velocimetry of the flow field around a sphere sedimenting near a wall Part 1. Effects of Weissenberg number, Journal of Non-Newtonian Fluid Mechanics, 141, 99-115.

22. Taylor, G.I. Proceedings of the Royal Society of London. Series A, Mathematical and Physical Sciences. 1950, 201, 192-196.

23. V. Tirtaatmadja, Uhlherr P.H.T., Sridhar T., (1990), Creeping motion of spheres in fluid, J. NonNewtonian Fluid Mech., 35, 327-337.

Table 1. Properties of the different liquids used in this study

Table 2. Various parameters of the different liquid-liquid systems used in this work

\section{Caption of figures}

Figure 1. Set up of the Particle Image Velocimetry (PIV) system.

Figure 2. Flow Fields around a settling sphere of $7.1 \mathrm{~mm}$ diameter. $U=0.57 \mathrm{~m} \cdot \mathrm{s}^{-1}$. $(\operatorname{Re}=17.18)$.

Figure 3. Sequence of interface breakthrough. (a) Evolution of the passage of a $4 \mathrm{~mm}$ glass sphere through the Silicone oil 10/HV45 50\% interface in function of the time. The rupture occurs $360 \mathrm{~ms}$ after the interface contact. (b) Temporary evolution of the sphere's position.

Figure 4. (a) Temporary evolution of the passage of spheres. (b) Evolution of the height of liquid entrained behind the sphere. Spheres having $4 \mathrm{~mm}$ (empty symbol) and $6 \mathrm{~mm}$ (full symbol) diameter at six different interfaces composed by Silicone oil 10, 50 and $100 \mathrm{mPa}$.s as light phase and HV45 50\% and 65\% wt as dense phase.

Figure 5. (a) Variation of the dimensionless ratio between the passage time of the particles over the characteristic time $t_{\mathrm{p}} / \mathrm{t}_{\mathrm{c}}$ in the various systems studied in function of the ratio between two Reynolds numbers $\left(\operatorname{Re}_{1} / \mathrm{Re}_{2}\right)$. (b) Variation of the dimensionless ratio between the height of liquid entrained behind the particle over its equivalent diameter $h_{\max } / d_{\text {eq }}$ in the various systems studied in function of the ratio between two Reynolds numbers $\left(\mathrm{Re}_{1} / \mathrm{Re}_{2}\right)$.

Figure 6. Example of images obtained by the PIV camera at the interface with seeding particles for Silicon oil $10 / \mathrm{HV} 4550 \%$ system (reflection comes from the interface). 
Figure 7. Flow fields around a $4 \mathrm{~mm}$ sphere diameter crossing an interface obtained by the PIV device. (a) $t=$ $0.1 \mathrm{sec}$ before the interface contact, (b) $\mathrm{t}=0.1 \mathrm{sec},(\mathrm{c}) \mathrm{t}=0.2 \mathrm{sec},(\mathrm{d}) \mathrm{t}=0.3 \mathrm{sec}$ after the interface contact.

Figure 8. Flow fields around a $6 \mathrm{~mm}$ sphere diameter crossing an interface obtained by the PIV device. (a) $\mathrm{t}=$ $0.1 \mathrm{~s}$, (b) $\mathrm{t}=0.15 \mathrm{~s},(\mathrm{c}) \mathrm{t}=0.2 \mathrm{~s},(\mathrm{~d}) \mathrm{t}=0.25 \mathrm{~s}$ after the interface contact.

Figure 9. Diagram of parity between experimental and correlated values of $t_{\mathrm{p}} / \mathrm{t}_{\mathrm{c}}$.(Eq 8)

Figure 10. Diagram of parity between experimental and correlated values of $h_{\max } / \mathrm{d}_{\mathrm{eq}}$ by equation (9).

Figure 11. Hydrodynamics instabilities observed for both passage of sphere and particle. Phase 1 is the initial contact phase and phase 2 the second phase. 


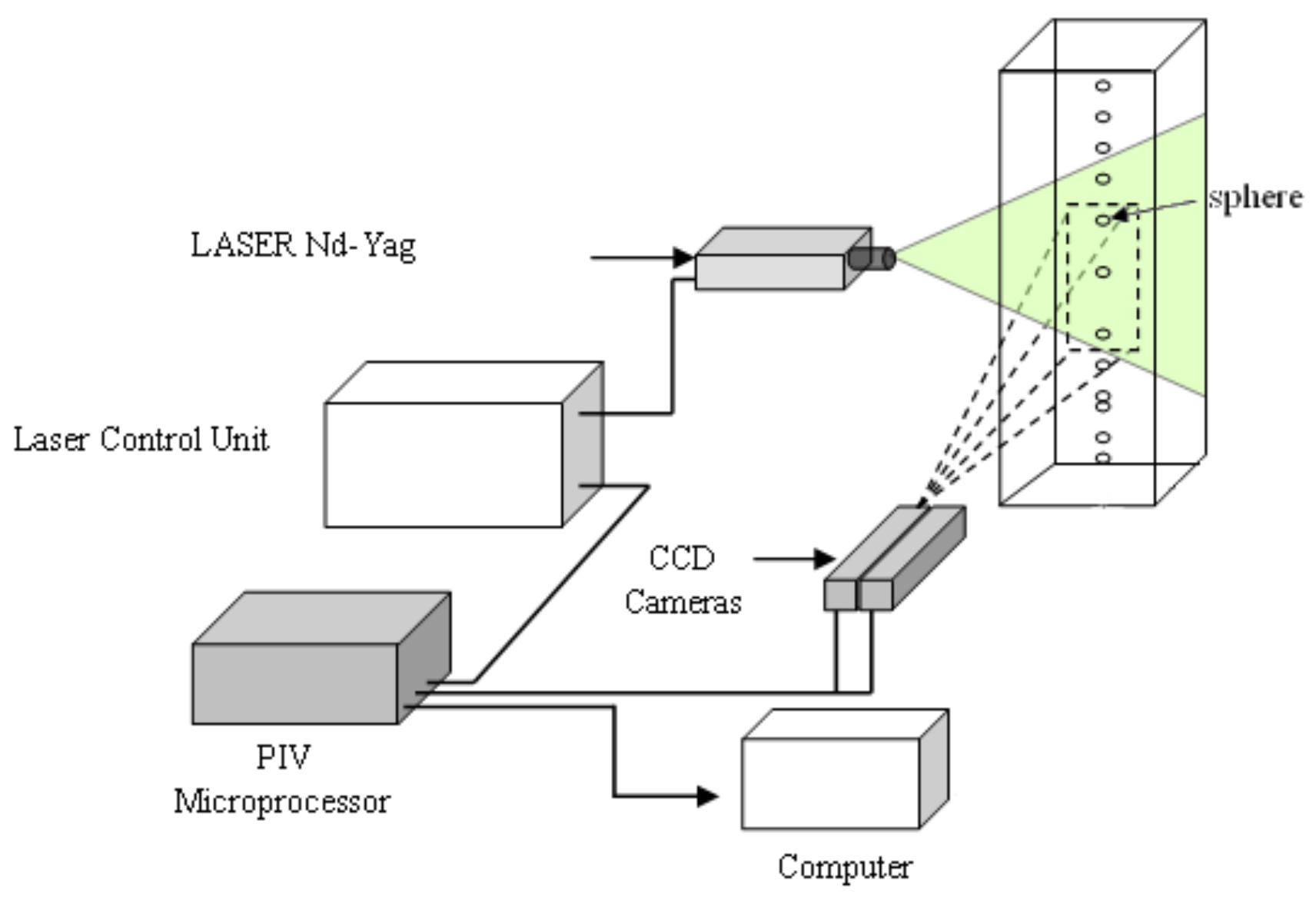

Figure 1. Set up of the Particle Image Velocimetry (PIV) system. 


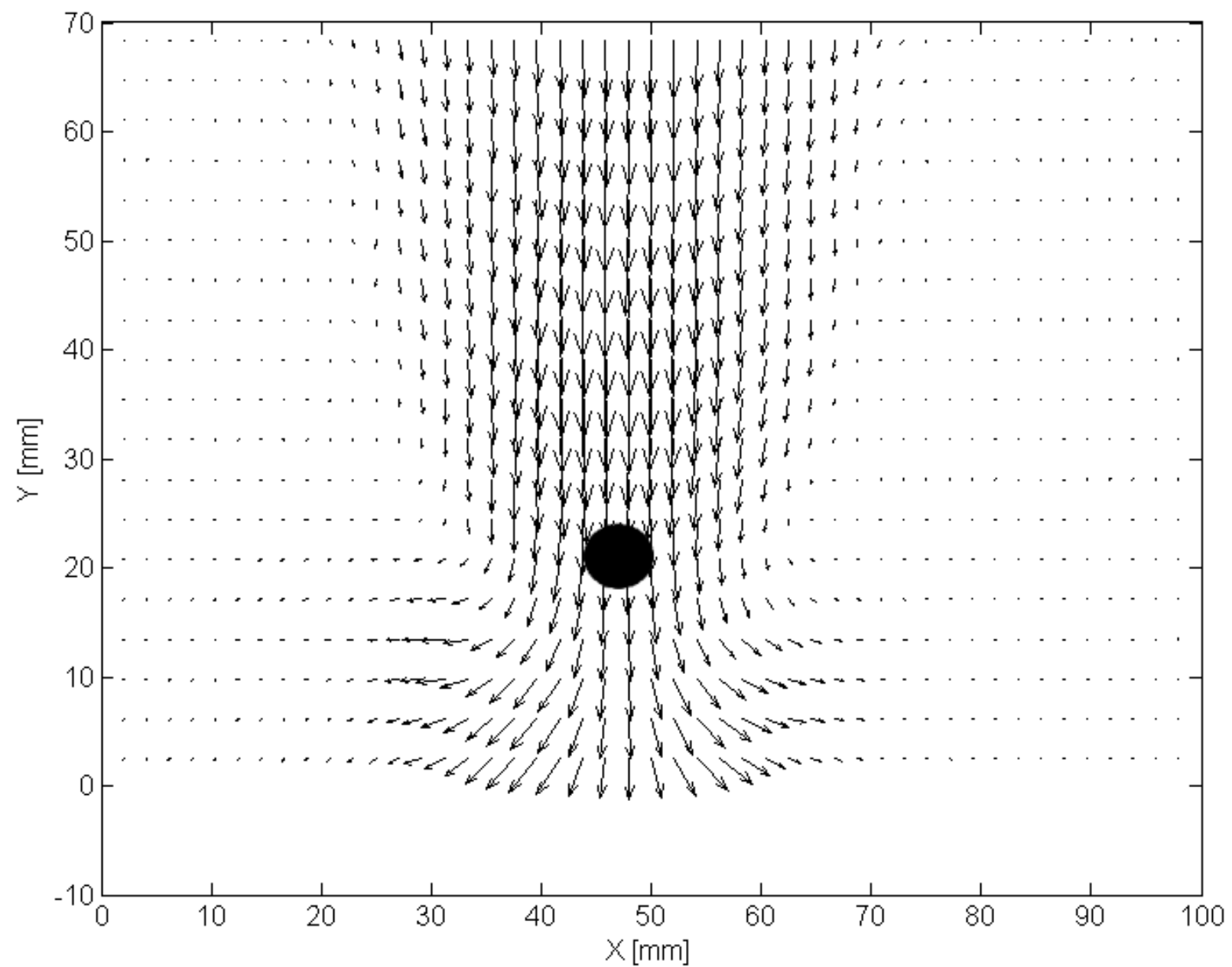

Figure 2. Flow Fields around a settling sphere of $7.1 \mathrm{~mm}$ diameter. $\mathrm{U}=0.57 \mathrm{~m} \cdot \mathrm{s}^{-1} .(\mathrm{Re}=17.18)$. 
(a)

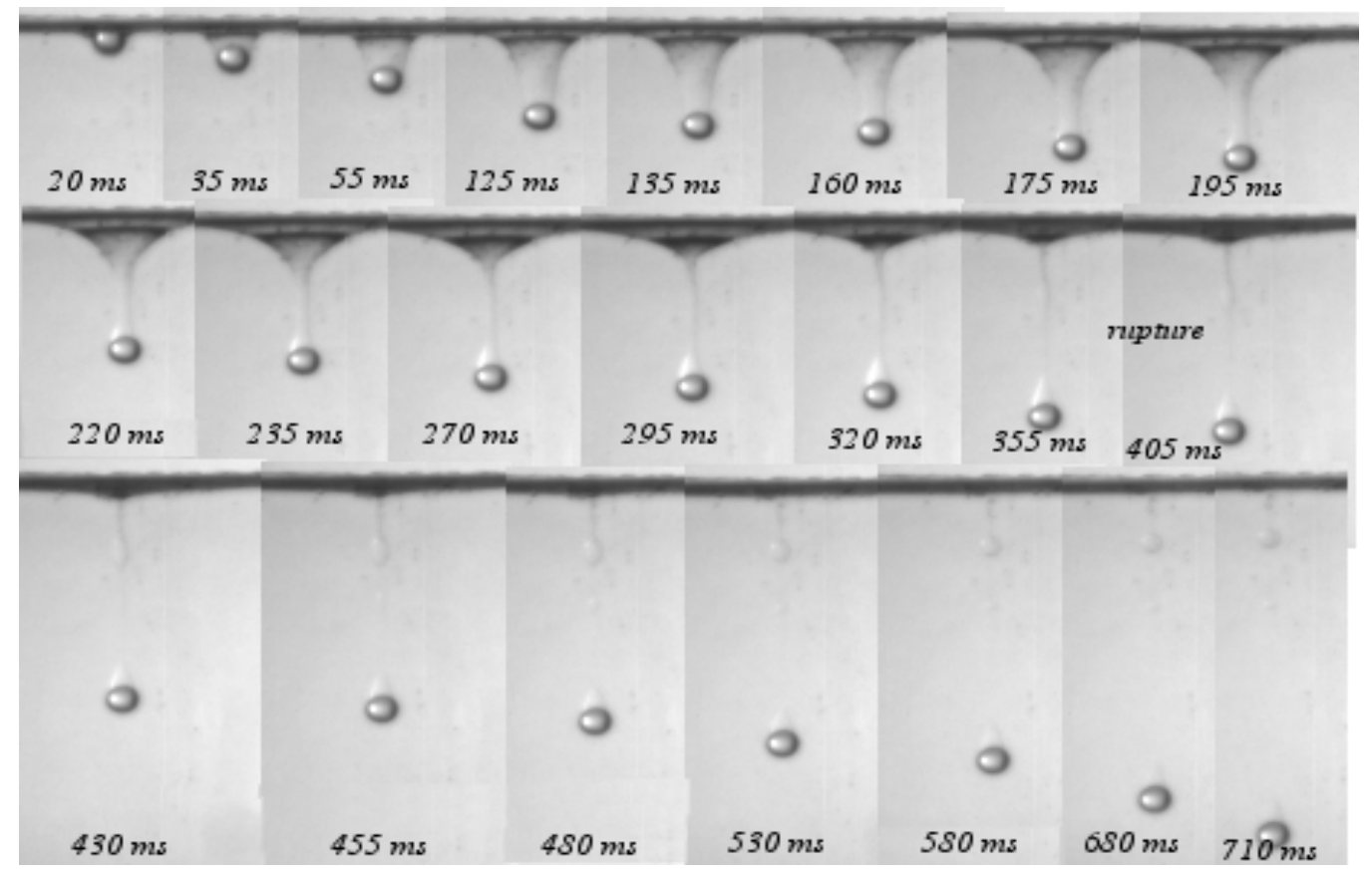

(b)

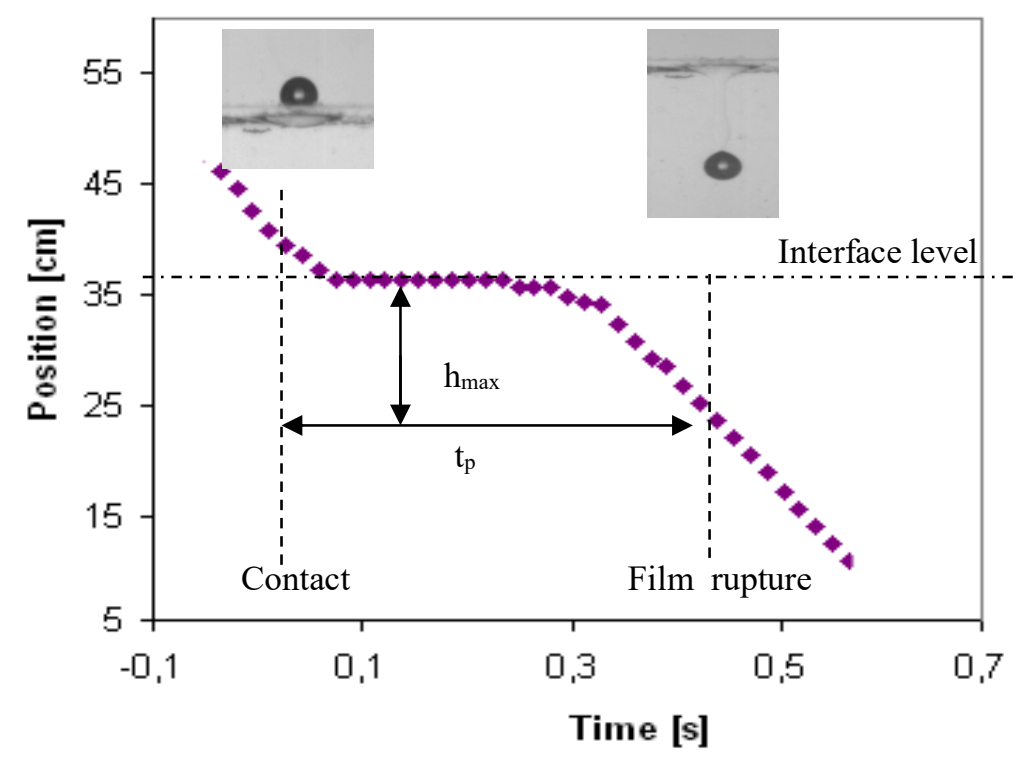

Figure 3. Sequence of interface breakthrough. (a) Evolution of the passage of a $4 \mathrm{~mm}$ glass sphere through the Silicone oil 10/HV45 50\% interface in function of the time. The rupture occurs $360 \mathrm{~ms}$ after the interface contact. (b) Temporary evolution of the sphere's position, defined by its center. 

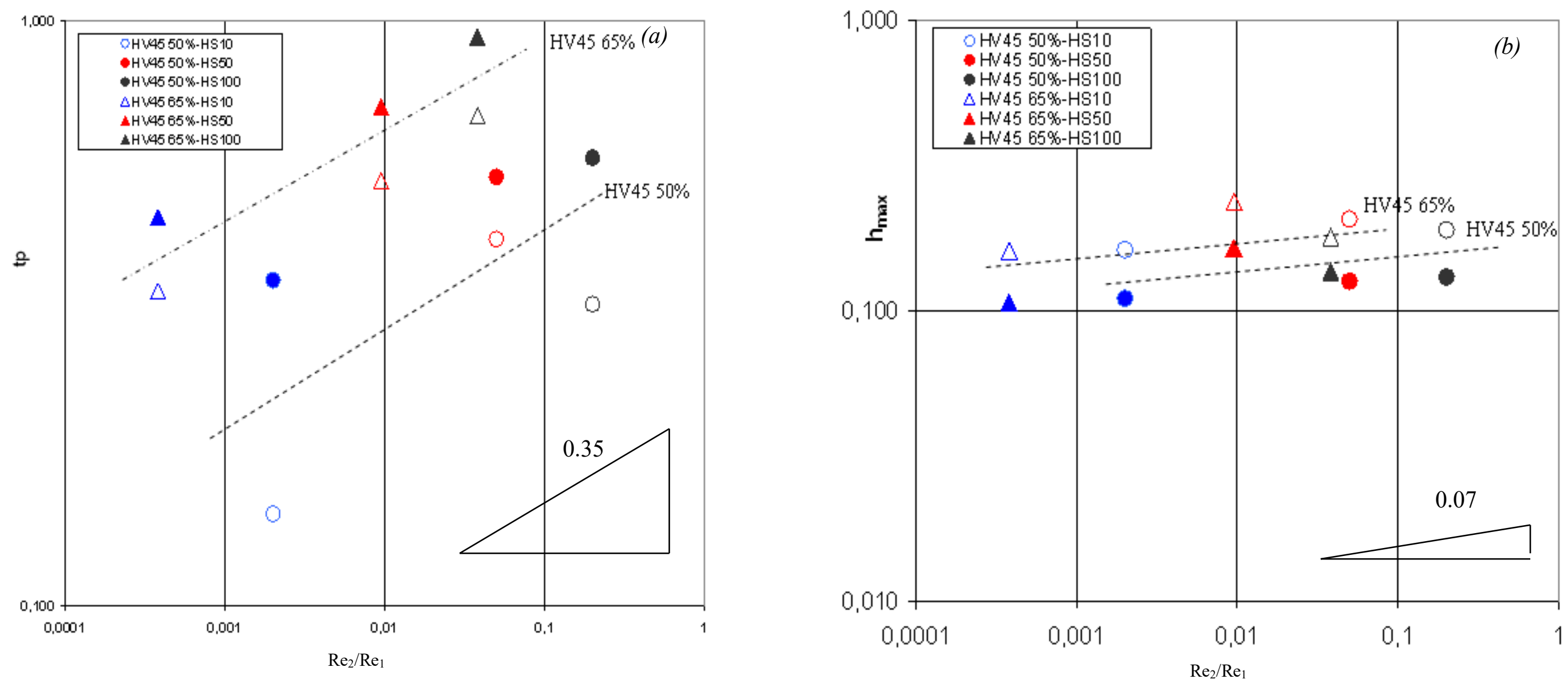

Figure 4. (a) Evolution of the passage time of spheres. (b) Evolution of the height of liquid entrained behind the sphere. Spheres of $4 \mathrm{~mm}$ (empty symbol) and $6 \mathrm{~mm}$ (full symbol) diameter at six different liquid-liquid interfaces composed by Silicone oil 10, 50 and $100 \mathrm{mPa}$.s as light phase and HV45 50\% and 65\% wt as dense phase. Dash line coresonf to the correlation established for each heavy liquid. 

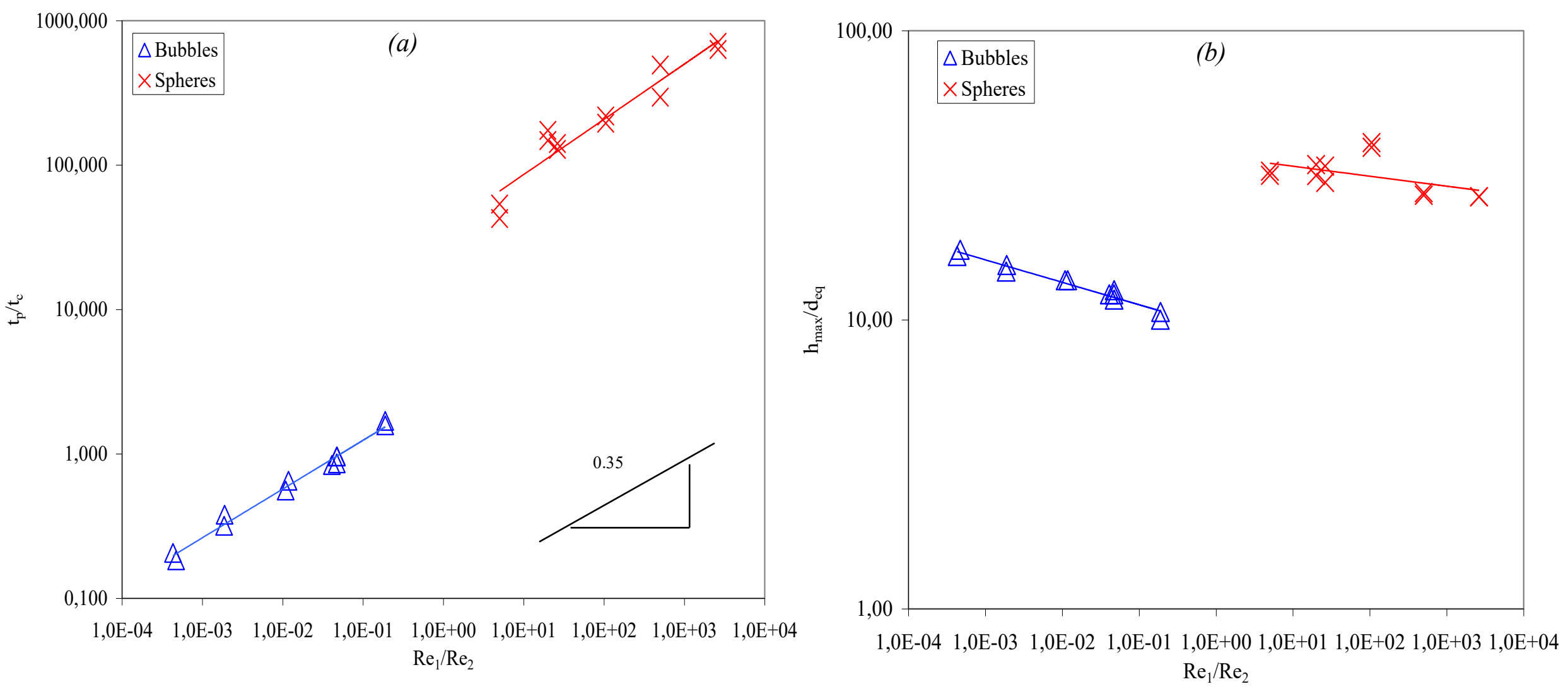

Figure 5. (a) Variation of the dimensionless passage time of the particles $t_{\mathrm{p}} / \mathrm{t}_{\mathrm{c}}$ in the various liquid-liquid systems studied in function of the ratio between two Reynolds numbers $\left(R e_{1} / R e_{2}\right)$. (b) Variation of the dimensionless height of liquid entrained behind the particle $h_{\max } / d_{e q}$ in these systems in function of $\operatorname{Re}_{1} / \operatorname{Re}_{2}$. 

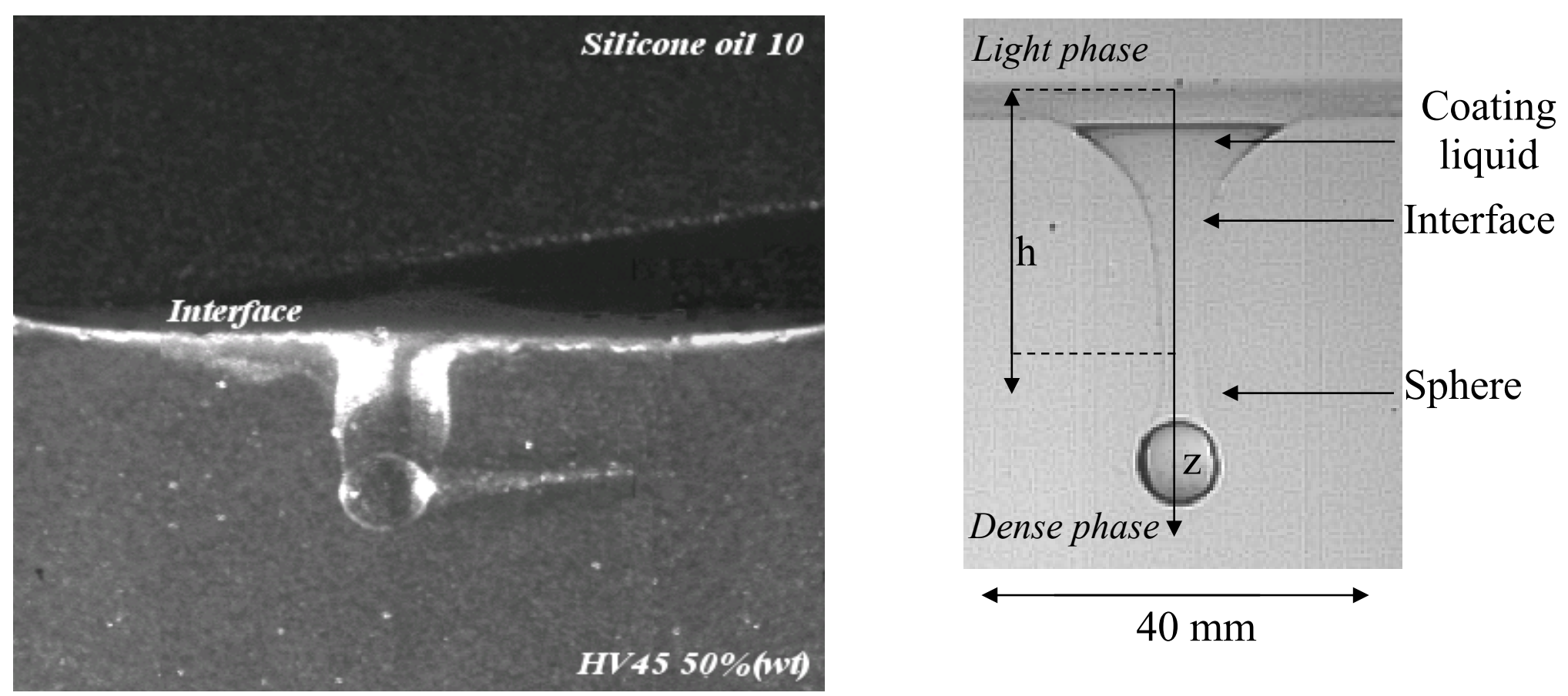

Figure 6. Example of images obtained by the PIV camera at the interface with seeding particles for Silicon oil $10 / \mathrm{HV} 45$ $50 \%$ system (reflection comes from the interface). 

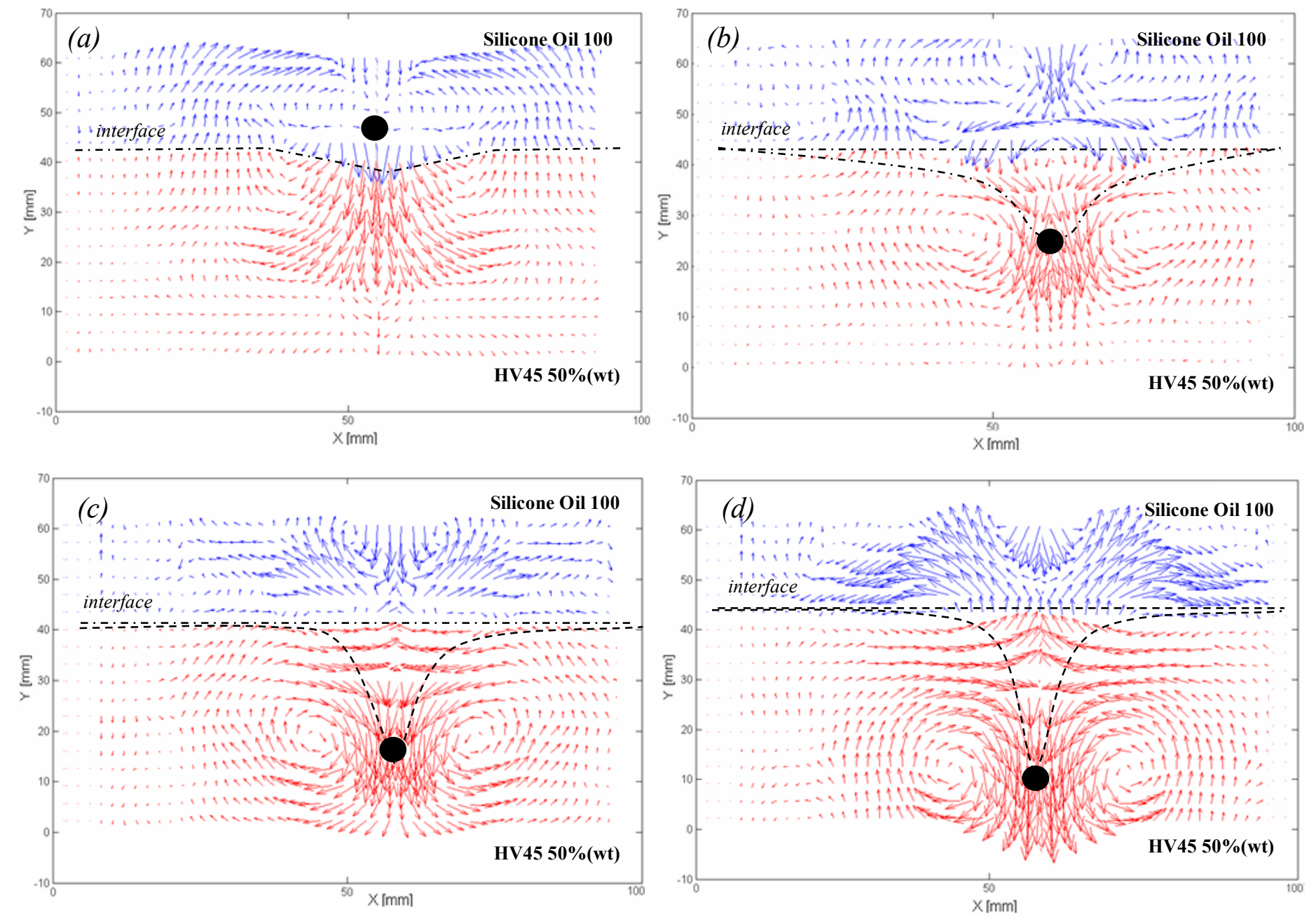

Figure 7. Flow fields around a $4 \mathrm{~mm}$ sphere diameter crossing an interface obtained by the PIV device. (a) $\mathrm{t}=0.1$ sec before the interface contact, (b) $t=0.1 \mathrm{sec}$, (c) $t=0.2 \mathrm{sec}$, (d) $\mathrm{t}=0.3 \mathrm{sec}$ after the interface contact. 

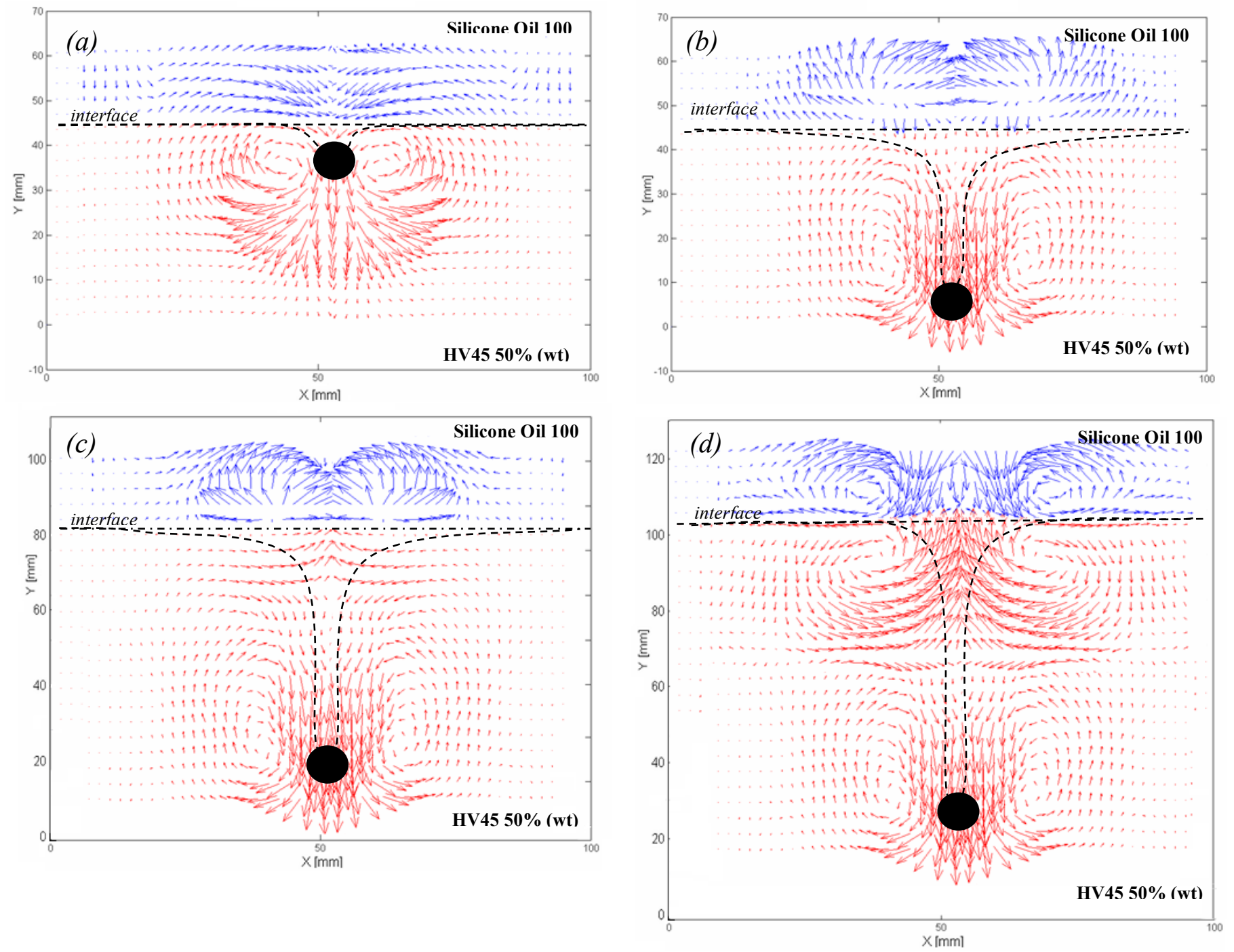
Figure 8. Flow fields around a $6 \mathrm{~mm}$ sphere diameter crossing an interface obtained by the PIV device. (a) $t=0.1 \mathrm{~s}$, (b) $t=$ $0.15 \mathrm{~s},(\mathrm{c}) t=0.2 \mathrm{~s}$, (d) $t=0.25 \mathrm{~s}$ after the interface contact.

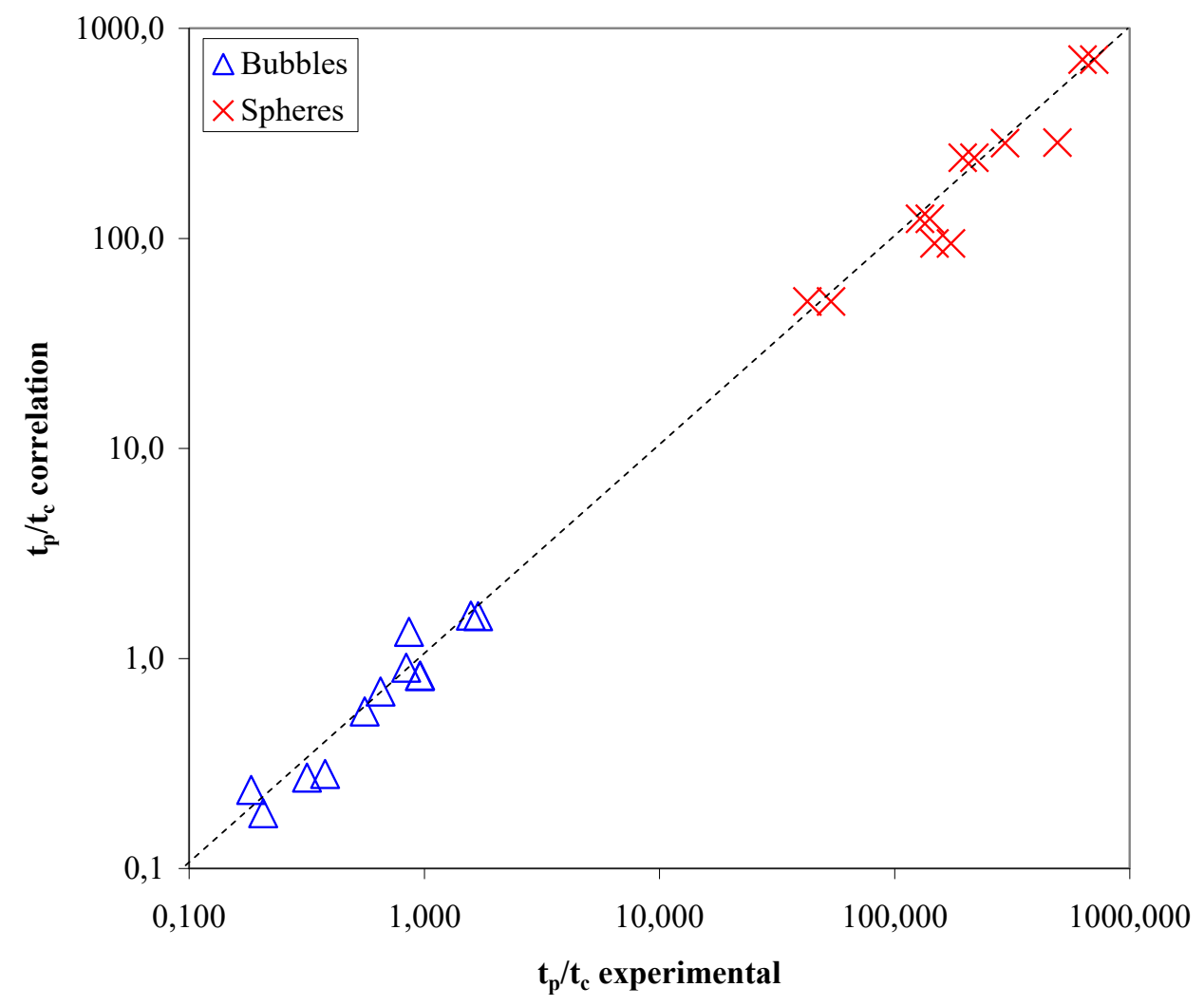

Figure 9. Parity diagram between the experimental and correlated values of $t_{\mathrm{p}} / \mathrm{t}_{\mathrm{c}}$ (Eq. 7). 


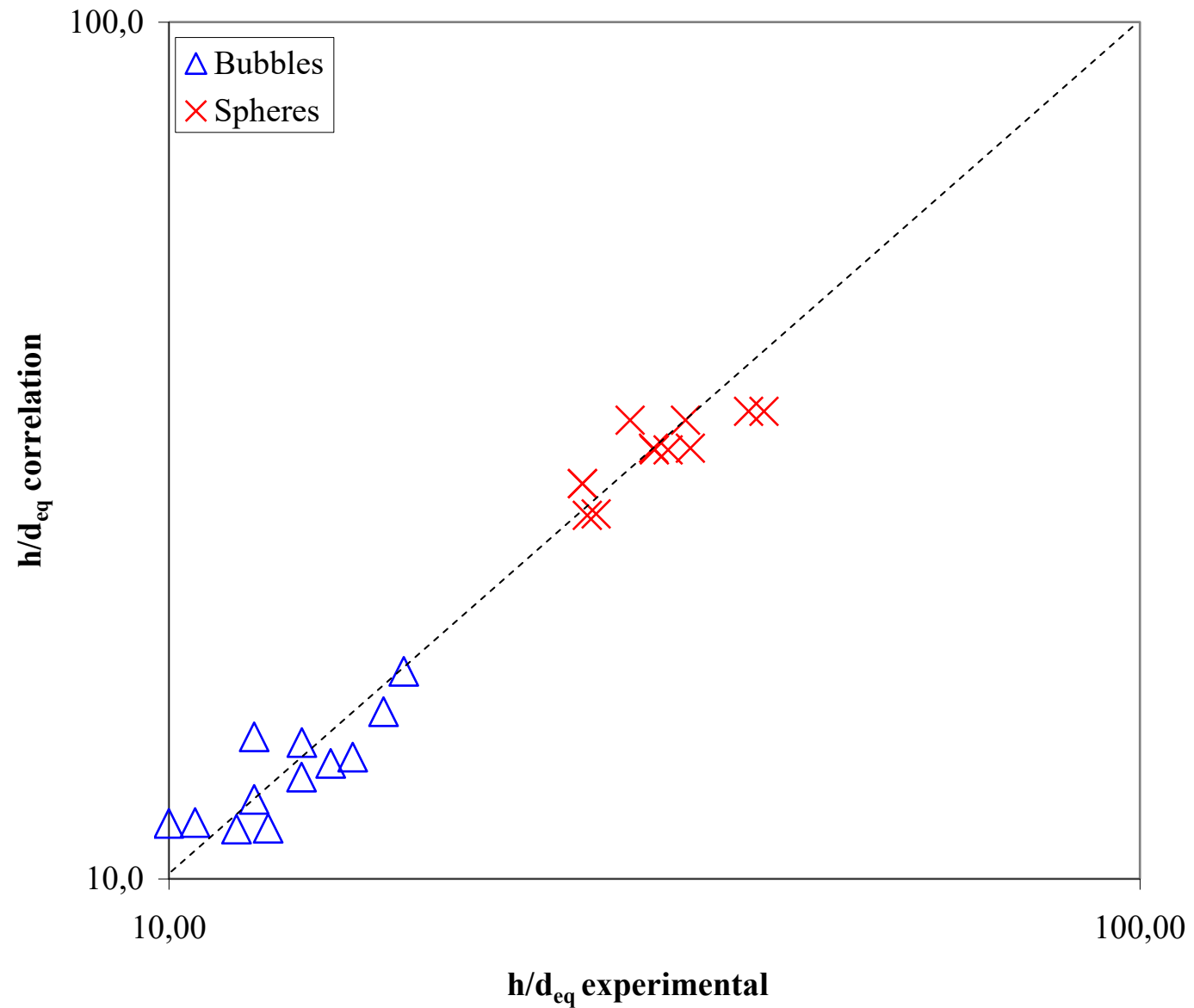


Figure 10. Parity diagram between the experimental and correlated values of $h / d_{e q}$.

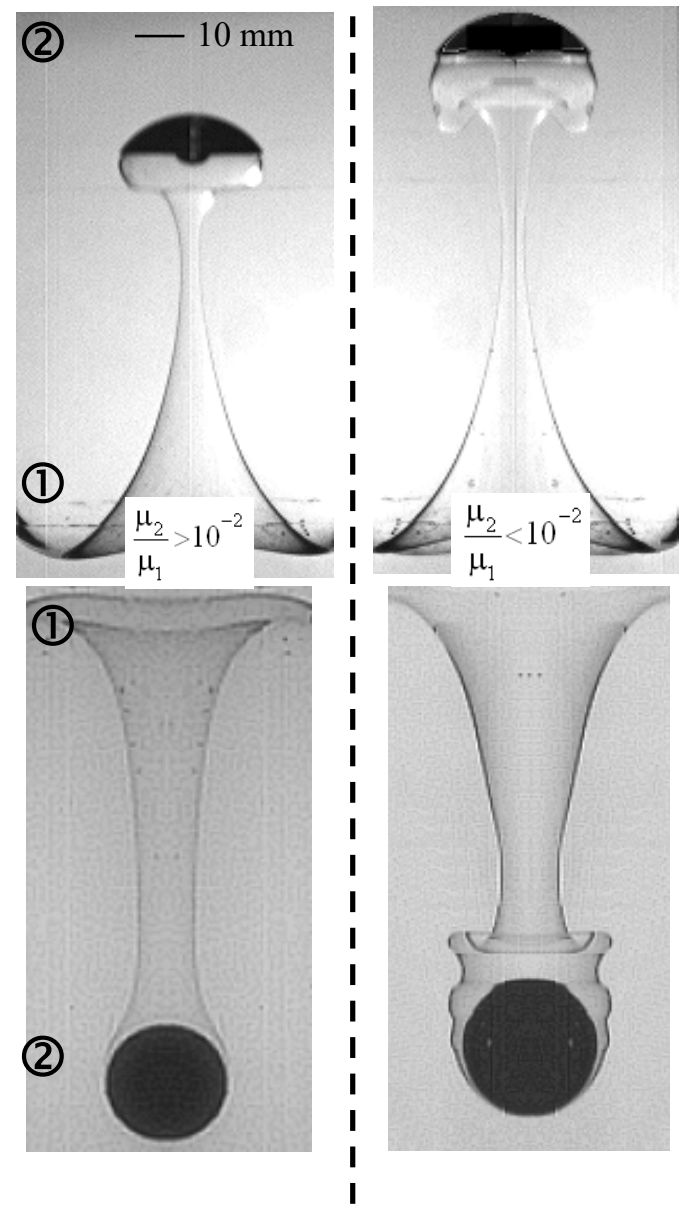


Figure 11. Hydrodynamic instabilities observed for the passage of both sphere and bubble. Phase 1 is the initial contact phase and phase 2 the second phase. 